\title{
Differences in Characteristics between Glycine and Glycylglycine Transport in Guinea Pig Small Intestine
}

\author{
Masayoshi HrmukaI,* Yuichi SuzuKI, and Takeshi Hoshi** \\ Department of Physiology, Tohoku University School of Medicine, \\ Seiryocho, Sendai, 980 Japan \\ **Department of Physiology, Faculty of Medicine, University of Tokyo, \\ Bunkyo-ku, Tokyo, 113 Japan
}

\begin{abstract}
The properties of glycylglycine and glycine transport across the mucosal border of the epithelium were studied in isolated guinea pig ileum. The initial influxes of both substances obeyed simple MichaelisMenten kinetics, but the values of the kinetic parameters were greatly different between two substances; $J_{\max }$ and $K_{\mathrm{t}}$ for glycine were $290 \mathrm{nmol}$ $\mathrm{cm}^{-2} \cdot \mathrm{min}^{-1}$ and $27 \mathrm{~mm}$, and those for glycylglycine were $57.4 \mathrm{nmol} \cdot$ $\mathrm{cm}^{-2} \cdot \mathrm{min}^{-1}$ and $3.4 \mathrm{mM}$, respectively. Total replacement of $\mathrm{Na}^{+}$in the incubation medium with mannitol completely suppressed the cellular uptake of glycine, while it reduced glycylglycine uptake only slightly. The omission of $\mathrm{Na}^{+}$caused a slight increase in $K_{\mathrm{t}}$ for glycylglycine (from $3.4 \mathrm{mM}$ at $100 \mathrm{mM} \mathrm{Na}{ }^{+}$to $5.2 \mathrm{mM}$ at $0 \mathrm{mM} \mathrm{Na}{ }^{+}$) without changing the value of $J_{\max }$. Glycylglycine taken up by the epithelial cells had been completely hydrolysed into glycine within 2 -min incubation period. The results of the present study seem to indicate that there are entirely distinct transport systems for glycine and its dimer and that the membrane digestion and subsequent transport as the monomer may not be involved in the absorption of glycylglycine.
\end{abstract}

During the past decade, it has become clearer that the main sites of the terminal digestion of carbohydrates or proteins in the small intestine are the surface of the brush border membrane (membrane digestion) and/or within the epithelial cells (intracellular hydrolysis). Disaccharides are known to be absorbed as monosaccharides after the membrane digestion (CRANE, 1968; UGOLEV, 1974), whereas oligopeptides are absorbed by two different processes; one is transport as amino acids after the membrane digestion and the other is transport of intact di- or tripeptides and subsequent intracellular hydrolysis (MATTHEws, 1975). Since NEWEY and SMYTH (1962), transport of intact di- or tripeptides has been

Received for publication April 5, 1978

* Present address: Department of Pediatrics, Tohoku University School of Medicine, Sendai, 980 Japan

日向正義, 鈴木裕一, 星 猛 
clearly demonstrated in the small intestine by the use of non-hydrolysed or poorly hydrolysed peptides such as glycylsarcosine (ADDISON et al., 1972), carnosine (MATTHEws et al., 1974) or glycylsarcosylsarcosine (ADDISON et al., 1975). These studies have also demonstrated the $\mathrm{Na}^{+}$-dependent uphill transport of these peptides.

Glycylglycine has been frequently used as a model dipeptide in the study of dipeptide transport. Some investigators have suggested that this dipeptide is transported as such by a system distinct from glycine transport system (NEwEY and Smyth, 1962; Matthews et al., 1968; AdiBI, 1971; AdiBI and SoleimanPour, 1974; UGOLEV, 1974). However, it seems still unknown as to whether transport of this dipeptide is entirely independent of glycine transport or to what extent the membrane digestion is involved in the absorption of this peptide.

The present study aimed at more precise characterization of transport of glycylglycine and glycine across the mucosal border of the small intestine in order to see the interrelationship between glycylglycine and glycine transport. The results show that the kinetic properties and $\mathrm{Na}^{+}$-dependence are greatly different between two substances, supporting the existence of distinct transport systems. Some of kinetic data suggest that the membrane digestion may not be involved in the process of glycylglycine absorption.

\section{METHODS}

Guinea pigs of both sex, weighing $450-600 \mathrm{~g}$, were used. The animals were maintained on normal diet until the days of experiments. After anesthetizing with urethane $(1 \mathrm{~g} / \mathrm{kg} \mathrm{B}$. W., intraperitoneal injection), the ileum was partially resected after a wide midline incision of the abdominal wall. When the basal anesthesia seemed insufficient, inhalation anesthesia with ether was complemented during the surgical operation. Usually, the distal half of the ileum, about $15 \mathrm{~cm}$ in length, was excised first, and the remaining part of the intestine was put back into the abdominal cavity, then the abdominal wall was closed with clamps. During the experiments with the distal ileum, the animal was kept warm under the basal anesthesia. After the first series of experiments (usually $1 \mathrm{hr}$ later from the first resection) the proximal ileum was excised for the second series of experiments. Our preliminary experiments revealed that the regional difference in glycylglycine and glycine transport along the small intestine was essentially the same as those of galactose and alanine transport (HosH et al., 1976), namely, flux values for these substances were about two-fold higher in the ileum than in the jejunum. Therefore, only the ileum was used throughout the present study.

The isolated ileum was divided into six small segments of $2 \mathrm{~cm}$ length, rinsed with oxygenated buffer solution containing $100 \mathrm{mM} \mathrm{Na}^{+}$, and then all segments were everted in a petri dish containing fresh oxygenated buffer solution. Each everted segment was fixed over a polyethylene tube $(5 \mathrm{~mm}$ in the outer diameter) 
and tied at the both ends with cotton threads. Each segment, thus fixed over the tube, was preincubated in $20 \mathrm{ml}$ oxygenated buffer solution (containing $100 \mathrm{~mm}$ $\mathrm{Na}^{+}$) at $37^{\circ} \mathrm{C}$ for $30 \mathrm{~min}$. When a test incubation medium differs in ionic composition from the preincubation medium, the everted segments were incubated for $1 \mathrm{~min}$ in the solution identical with the test medium just before the start of the test incubation. The standard buffer solution employed in the present study had the following composition (in $\mathrm{mM}$ ): $\mathrm{Na}_{2} \mathrm{SO}_{4} 50$, mannitol 160, $\mathrm{KHCO}_{3} 2.5, \mathrm{KH}_{2} \mathrm{PO}_{4}$ $0.25, \mathrm{CaSO}_{4} 1.5, \mathrm{MgSO}_{4} 1.4$, Tris- $\mathrm{H}_{2} \mathrm{SO}_{4} 20\left(\mathrm{pH} 7.4\right.$ at $\left.37^{\circ} \mathrm{C}\right)$, and osmolality 290 $\mathrm{mOsm} / \mathrm{kg} \mathrm{H}_{2} \mathrm{O}$. The reason for use of the $\mathrm{SO}_{4}^{--}$-medium is that the study of interrelationship between the influx and electrical potential change (the transport potential), which will be dealt with in a subsequent paper, is much easier in the $\mathrm{SO}_{4}^{--}$-medium since larger and more stable transport potentials can be recorded in this type of medium than in the $\mathrm{Cl}^{-}$-medium (HosH et al., 1976). In regard to influx values for glycine, there was no significant difference between the $\mathrm{SO}_{4}^{--}$and $\mathrm{Cl}^{-}$-media (see Results, Table 1). The test media of various $\mathrm{Na}^{+}$concentrations were prepared by replacing $\mathrm{Na}_{2} \mathrm{SO}_{4}$ with mannitol without changing the osmolality of the solutions.

The uptake of glycylglycine or glycine from the mucosal bathing fluid was measured by tracer techniques using $\left[1-{ }^{14} \mathrm{C}\right]$ glycylglycine $(0.1 \mu \mathrm{Ci} / \mathrm{ml})$ or $\left[2-{ }^{14} \mathrm{C}\right]$ glycine $(0.1 \mu \mathrm{Ci} / \mathrm{ml})$ and $\mathrm{D}-\left[1-{ }^{3} \mathrm{H}\right]$ mannitol $(1 \mu \mathrm{Ci} / \mathrm{ml}) . \quad\left[{ }^{3} \mathrm{H}\right]$ mannitol was used for the purpose of estimating amounts of adhering mucosal fluid and extracellular space of the mucosal surface. Immediately after the end of the incubation, the preparation was rinsed with ice-cold isotonic mannitol solution for $5 \mathrm{sec}$, blotted, detached from the polyethylene tube and then put in $3 \mathrm{ml}$ of $3 \%$ trichloroacetic acid. The extraction tubes were shaken overnight at room temperature. The isotonic mannitol solution used for rinsing was collected and its radioactivities were measured for ${ }^{14} \mathrm{C}$ and ${ }^{3} \mathrm{H}$. The ratio of ${ }^{14} \mathrm{C}$ and ${ }^{3} \mathrm{H}$ activities was found to be identical with that of the incubation medium, indicating that there was practically no exit of glycine or glycylglycine from inside the cells during the period of rinsing. The radioactivities of the extraction fluid and the test medium were counted in a liquid scintillation counter (Aloka LSC 602) by using Bray's solution. All data of cellular uptake rate were presented as mean \pm S.E. $\left(\mathrm{nmol} \cdot \mathrm{cm}^{-2} \cdot \mathrm{min}^{-1}\right)$. The number of observations (given in parentheses) was equal to the number of animals examined unless otherwise noticed. The ratio of wet weight to the serosal surface area was $52 \pm 4.1 \mathrm{mg} / \mathrm{cm}^{2}(n=8)$.

In some experiments, glycine concentrations in the incubation media and tissue water were determined chemically by the method of SARDESAI and Provido (1970). In such experiments, the test solutions were buffered with phosphate ( $2 \mathrm{mM} \mathrm{K}_{2} \mathrm{HPO}_{4}$ plus $0.5 \mathrm{mM} \mathrm{KH}_{2} \mathrm{PO}_{4}$ ), since Tris interferred with the color reaction of glycine in this method. Trichloroacetic acid $(3 \%)$ did not interfere with the color reaction. Tissue concentrations of glycine after incubation with glycine or glycylglycine were corrected for intrinsic glycine which were determined in sam- 
ples taken from portions immediately adjacent to those employed for the uptake experiments.

\section{RESULTS}

Time course of uptake

First the time course of uptake was examined for both glycine and glycylglycine. It was seen that the uptake in the presence of $100 \mathrm{mM} \mathrm{Na}{ }^{+}$increased linearly with time up to $2 \mathrm{~min}$ in both cases, thereafter the uptake rates gradually slowed down (Fig. 1). Therefore, in the subsequent experiments, 2-min incubation was adopted to determine the initial influxes across the mucosal border.

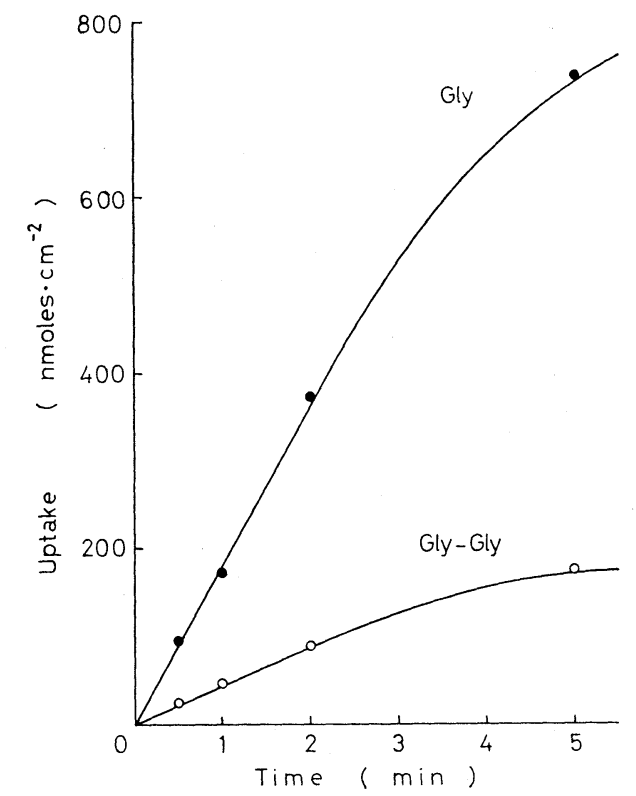

Fig. 1. Time courses of uptake of glycine and glycylglycine in the presence of $\mathrm{Na}^{+}$at $100 \mathrm{~mm}$. Glycine uptake (Gly) was measured in the medium containing $40 \mathrm{~mm}$ glycine, whereas glycylglycine uptake (Gly-Gly) was determined at $10 \mathrm{~mm}$ glycylglycine.

Differences in kinetic properties between glycylglycine and glycine transport

In the standard medium $\left(\mathrm{Na}^{+}\right.$concentration $100 \mathrm{mM}$ ) both the rates of glycine and glycylglycine uptake appeared to conform to single Michaelis-Menten kinetics, as indicated by a linear line in the Lineweaver-Burk plots of the data (Fig. 2). The values of the half saturation concentration, $K_{\mathrm{t}}$, were $27 \mathrm{~mm}$ for glycine and $3.4 \mathrm{~mm}$ for glycylglycine. The values of the maximal influx, $J_{\max }$, were $290 \mathrm{nmol}$. $\mathrm{cm}^{-2} \cdot \min ^{-1}$ for glycine and $57.4 \mathrm{nmol} \cdot \mathrm{cm}^{-2} \cdot \min ^{-1}$ for glycylglycine. Thus, the values of $J_{\max }$ are greatly different between these two substances, the values 


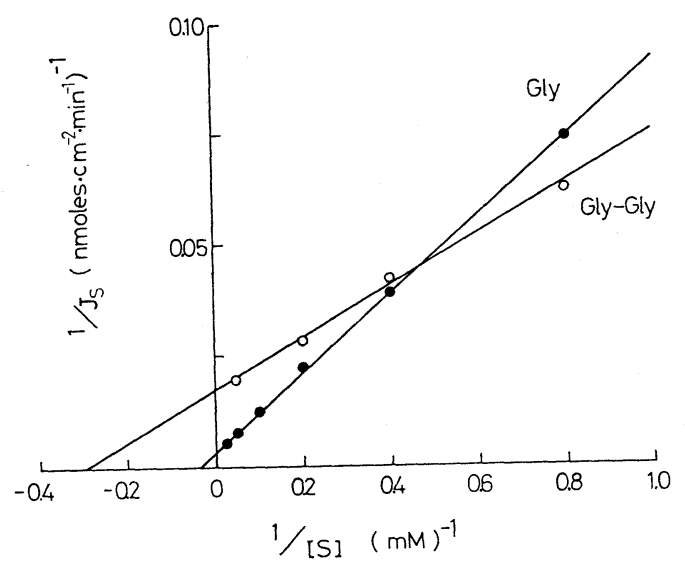

Fig. 2. Lineweaver-Burk plots of initial influxes of glycylglycine (open circles) and glycine (closed circles) across the mucosal border of everted ileal preparations. $\mathrm{Na}^{+}$concentration in the incubation media was fixed at $100 \mathrm{~mm}$. Each value is the mean of five or six measurements.

for glycine being about 5 times higher than that of glycylglycine. On the other hand, the affinity of glycine for its transport system is much lower than that of glycylglycine. Such marked differences in the kinetic parameters indicate that these two substances are transported by distinct transport systems. As compared with glycine transport, glycylglycine transport system can be characterized by a relatively high affinity but a low transport capacity.

\section{Difference in sodium effect on influxes}

There were marked differences in effect of medium $\mathrm{Na}^{+}$concentration on influx between glycine and glycylglycine. In the case of glycine, reduction of medium $\mathrm{Na}^{+}$concentration lowered the rate of uptake, and the cellular uptake rate became virtually zero when external $\mathrm{Na}^{+}$was totally eliminated (Fig. 3A). The Michaelis-Menten type relation was seen in the activating effect of $\mathrm{Na}^{+}$, and the half saturation concentration for $\mathrm{Na}^{+}$was $15.6 \mathrm{~mm}$ at $20 \mathrm{~mm}$ glycine.

On the other hand, the effect of changing medium $\mathrm{Na}^{+}$concentration was relatively small in the case of glycylglycine (Fig. 3B). As shown in Fig. 4, total elimination of $\mathrm{Na}^{+}$from the incubation medium caused only a slight increase in $K_{\mathrm{t}}$ without affecting the value of $J_{\max }$. The value of $K_{\mathrm{t}}$ increased from $3.4 \mathrm{~mm}$ at $100 \mathrm{mM} \mathrm{Na}^{+}$to $5.2 \mathrm{mM}$ at $0 \mathrm{mM} \mathrm{Na}{ }^{+}$. When measured at $5 \mathrm{mM}$ glycylglycine in the mucosal solution, the elimination of $\mathrm{Na}^{+}$reduced glycylglycine influx to $74 \%$ of control value (at $100 \mathrm{mM} \mathrm{Na}^{+}$). Thus, glycylglycine transport can be characterized by a very weak $\mathrm{Na}^{+}$activation in contrast to glycine transport. Although the relationship between the $K_{\mathrm{t}}$ value and the $\mathrm{Na}^{+}$concentration could not exactly be determined because of a very small $\mathrm{Na}^{+}$effect, the $\mathrm{Na}^{+}$effect on glycylglycine transport appeared to be the same as the K-type (affinity type) effect of $\mathrm{Na}^{+}$on 
A)

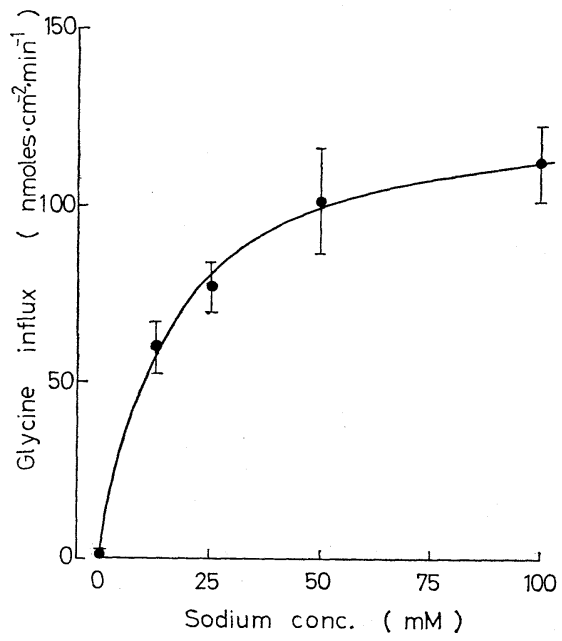

B)

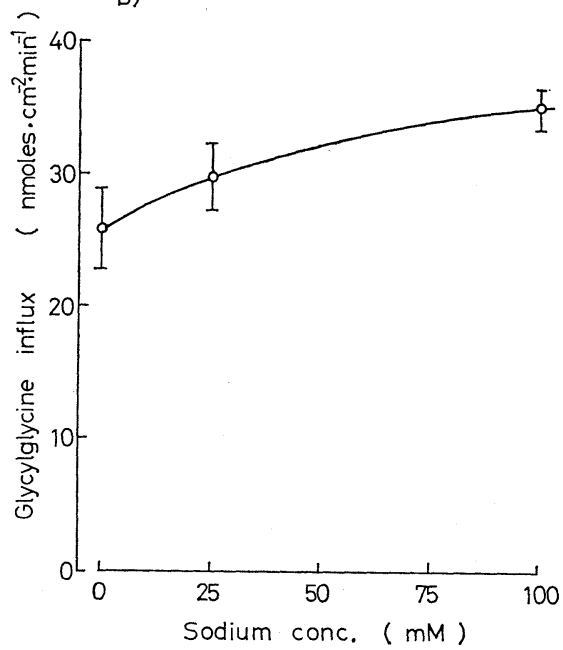

Fig. 3. The effect of medium $\mathrm{Na}^{+}$concentration on glycine (A) and glycylglycine (B) influxes. Glycine and glycylglycine concentrations in the incubation media were fixed at $20 \mathrm{~mm}$ and $5 \mathrm{~mm}$, respectively. Each value is mean \pm S.E. $(n=4$ for glycine and $8-10$ for glycylglycine).

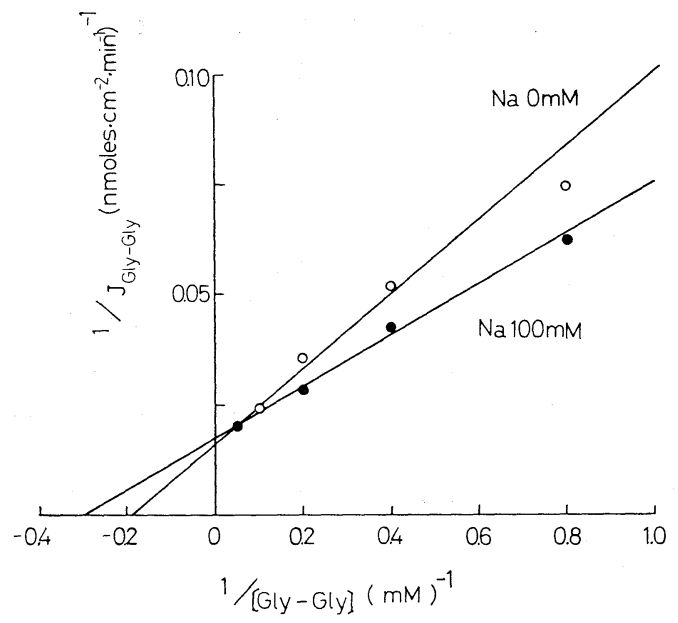

Fig. 4. Lineweaver-Burk plots of glycylglycine influxes measured in the presence of $100 \mathrm{~mm}$ $\mathrm{Na}^{+}$(closed circles) and in the absence of $\mathrm{Na}^{+}$(open circles). Each value is the mean of six to eight measurements.

alanine transport in the rabbit ileum (CURRAN et al., 1967).

An additional experiment showed that the replacement of $\mathrm{SO}_{4}^{--}$by $\mathrm{Cl}^{-}$had no significant effect on glycine influxes (Table 1). 
Table 1. Effect of principal anion in the medium on glycine influx. Glycine concentration in the incubation media was $20 \mathrm{~mm}$. The composition of the $\mathrm{SO}_{4}^{--}$-medium was the same as the standard buffer solution described in Methods. The $\mathrm{Cl}^{-}$-medium contained $100 \mathrm{~mm} \mathrm{NaCl}$ instead or $50 \mathrm{~mm} \mathrm{Na} \mathrm{NO}_{4}$ and $20 \mathrm{~mm}$ Tris-Cl instead of $20 \mathrm{~mm}$ Tris- $\mathrm{SO}_{4}$. The osmolality was adjusted by changing the amount of mannitol to be added. Values are given as mean \pm S.E.

\begin{tabular}{ccc}
\hline Medium & Glycine influx $\left(\mathrm{nmol} \cdot \mathrm{cm}^{-2} \cdot \mathrm{min}^{-1}\right)$ & $P$ (paired $t$-test) \\
\hline $\mathrm{SO}_{4}^{--}$-medium & $112.5 \pm 10.6(n=4)$ & $P>0.5$ \\
$\mathrm{Cl}^{-}$-medium & $109.8 \pm 9.0(n=4)$ & \\
\hline
\end{tabular}

\section{Intracellular hydrolysis of glycylglycine}

The results described above show that glycylglycine is transported by a poorly $\mathrm{Na}^{+}$-activated carrier-mediated mechanism distinct from glycine transport system. In order to see the state of glycylglycine after the luminal transport, tissue concentration of free glycine at the end of 2-min incubation period was measured chemically. The data obtained are shown in Table 2, which show that glycylglycine taken up by the cells had been hydrolysed almost completely within 2 min regardless of the presence or absence of $\mathrm{Na}^{+}$in the outside medium.

Table 2. Comparison of the amounts of glycylglycine taken up by the tissues during 2-min incubation and tissue content of free glycine at the end of the incubation period ( $2 \mathrm{~min}$ ). Two different medium conditions were examined; the standard and $\mathrm{Na}^{+}$-free media. The initial medium concentration of glycylglycine was $10 \mathrm{~mm}$. The uptake was measured with radioactive glycylglycine, while free glycine was determined chemically.

\begin{tabular}{ccc}
\hline Medium & $\begin{array}{c}\text { Amount of Gly-Gly } \\
\text { taken up during } 2 \text { min } \\
\left(\mathrm{nmol} \cdot \mathrm{cm}^{-2}\right)\end{array}$ & $\begin{array}{c}\text { Tissue content of Gly } \\
\text { after } 2 \text { min incubation* } \\
\left(\mathrm{nmol} \cdot \mathrm{cm}^{-2}\right)\end{array}$ \\
\hline Standard medium & $92.0 \quad(n=6)$ & $200 \quad(n=3)$ \\
$\mathrm{Na}^{+}$-free medium & $83.4 \quad(n=6)$ & $162 \quad(n=3)$ \\
\hline
\end{tabular}

* Tissue content of glycine was corrected for intrinsic glycine.

\section{Mutual inhibition between glycine and glycylglycine}

Although kinetic data suggest that the transport systems for glycine and glycylglycine are separated, some mutual inhibition was observed between these substances. In the presence of $\mathrm{Na}^{+}$, glycine influx from $20 \mathrm{~mm}$ glycine solution was inhibited by about $30 \%$ by the presence of $10 \mathrm{~mm}$ glycylglycine (Table $3 \mathrm{a}$ ). The effect of glycine on glycylglycine uptake was determined in the absence of $\mathrm{Na}^{+}$in order to exclude the possibility of inhibition through the depolarization of the mucosal membrane (MURER and Hopfer, 1974; Hoshi and KiKUTA, 1977) or "trans $\mathrm{Na}^{+}$effect" (SEMENZA, 1971). As described above, glycine uptake is absolutely dependent on $\mathrm{Na}^{+}$whereas glycylglycine uptake is only partly dependent on $\mathrm{Na}^{+}$. Therefore, this series of experiments aimed at observing the direct effect of glycine on $\mathrm{Na}^{+}$-independent carrier-mediated transport of glycylglycine. As 
Table 3. Mutual inhibition of transport between glycine and glycylglycine. Values of influx are given as mean \pm S.E.

\begin{tabular}{llllllrl}
\hline Medium & $\begin{array}{c}\text { Substrate } \\
(\mathrm{mM})\end{array}$ & $n$ & $\begin{array}{c}\text { Inhibitor } \\
(\mathrm{mM})\end{array}$ & \multicolumn{2}{c}{$\begin{array}{c}\text { Influx } \\
\left(\mathrm{nmol} \cdot \mathrm{cm}^{-2} \cdot \mathrm{min}^{-1}\right)\end{array}$} & $\begin{array}{c}\% \\
\text { of } \\
J_{\mathrm{G} 1 \mathrm{y}}\end{array}$ & $\begin{array}{c}P \\
J_{\mathrm{G} 1 \mathrm{y}-\mathrm{Gl}}\end{array}$ \\
control & (paired $t$-test) \\
\hline a) $100 \mathrm{mM} \mathrm{Na}^{+}$ & Gly (20) & 6 & Nil & $124.0 \pm 12.2$ & 100 & \\
& Gly (20) & 6 & Gly-Gly(10) & $83.8 \pm 11.7$ & 68 & $P<0.05$ \\
b) $0 \mathrm{mM} \mathrm{Na}^{+}$ & Gly-Gly (5) & 4 & Nil & $26.5 \pm 4.0$ & 100 & \\
& Gly-Gly (5) & 4 & Gly (40) & $20.9 \pm 3.0$ & 79 & $P<0.02$ \\
& Gly-Gly (5) & 4 & Nil & $35.1 \pm 2.3$ & 100 & \\
c) $100 \mathrm{mM} \mathrm{Na}^{+}$ & Gly-Gly (5) & 4 & Gly-L-Leu (5) & $4.9 \pm 0.2$ & 14 & $P<0.001$ \\
\hline
\end{tabular}

shown in Table $3 \mathrm{~b}$, glycylglycine uptake was slightly but significantly reduced (by about $20 \%$ ) by the presence of $40 \mathrm{~mm}$ glycine $(0.01<P<0.02)$.

In additional experiments, the effect of glycyl-L-leucine on glycylglycine transport was examined in the presence of $\mathrm{Na}^{+}$(Table $3 \mathrm{c}$ ). In this case, glycylglycine influx from $5 \mathrm{~mm}$ solution was strongly inhibited by the presence of $5 \mathrm{~mm}$ glycylL-leucine, the percent inhibition being $86 \%$.

\section{DISCUSSION}

The results of the present study clearly show that glycylglycine and glycine are transported across the mucosal border by separate transport systems in the guinea pig small intestine. The data of kinetic study indicate that transport of both substances conforms to different single Michaelis-Menten kinetics and the values of the kinetic parameters $\left(J_{\max }\right.$ and $\left.K_{\mathrm{t}}\right)$ are greatly different between two substances. Lineweaver-Burk type plot of influx data for both substances revealed entirely independent straight lines. Such independent nature of kinetics is a sharp contrast to the kinetic relation of maltose or trehalose absorption to glucose transport. Maltose and trehalose are known to be typical substances which are absorbed as glucose after the membrane digestion. We previously showed that the double reciprocal plots of the maltose- or trehalose-induced potential changes across the intestine versus the mucosal concentration of the disaccharide revealed a unique relation to the same type plots for the glucose-induced potential changes (IGARASHI et al., 1976). Except for very high concentrations, the line for the dimer (maltose or trehalose) is linear and the extrapolation of the linear segment intercepts the ordinate at the point common with that for the line of its monomer (glucose). No such a relation or tendency was observed in the plots for glycylglycine and its monomer. Different features of $\mathrm{Na}^{+}$-dependence of transport also suggest the existence of distinct transport systems.

Glycylglycine transport resembles neutral amino acid transport by the rabbit ileum (CURRAN et al., 1967) in the following aspects: (1) The transport is only partially dependent on $\mathrm{Na}^{+},(2)$ The value of $J_{\max }$ is independent of presence of $\mathrm{Na}^{+}$ in the medium. The presence of $\mathrm{Na}^{+}$-dependent component in glycylglycine 
influx is supported by the fact that this dipeptide, as well as glycine, evokes an increment of the transmural potential when added to the mucosal side(KoHN et al., 1968). The quantitative relationship between the value of $K_{\mathrm{t}}$ and $\mathrm{Na}^{+}$concentration of the medium could not be obtained in glycylglycine transport because $\mathrm{Na}^{+}$stimulated component of its influx is so small. However, the similarities of basic properties of mucosal influx as described above may permit the use of the same kinetic model as that proposed for alanine transport by the rabbit ileum (CURRAN et al., 1967). Similarly to alanine transport, the carrier-glycylglycine-Na ternary complex (XSNa) is assumed to be formed in the following sequence: $\mathrm{X}+\mathrm{S} \rightleftharpoons \mathrm{XS}$ (dissociation const. $K_{1}$ ), $\mathrm{XS}+\mathrm{Na} \rightleftharpoons \mathrm{XSNa}$ (dissociation const. $K_{2}$ ), and S (glycylglycine) is assumed to be translocated in two forms, XS and XSNa, with an identical rate constant. Based on this model, the initial influx of glycylglycine can be given by the following equation:

$$
J=J_{\max } \frac{[\mathrm{S}]}{\frac{K_{1} K_{2}}{K_{2}+\left[\mathrm{Na}^{+}\right]}+[\mathrm{S}]}
$$

where [S] and $\left[\mathrm{Na}^{+}\right]$are the concentrations of glycylglycine and $\mathrm{Na}^{+}$in the mucosal solution, respectively. The value of $K_{2}$ for glycylglycine calculated by using this equation is $177 \mathrm{~mm}$, the value being much higher than the values for neutral amino acids(17-25 mM) in the rabbit ileum (SCHULTZ et al., 1970). This indicates that the interaction of $\mathrm{Na}^{+}$with glycylglycine is much weaker than in the case of amino acids.

The fact that the total elimination of $\mathrm{Na}^{+}$does not affect the value of $J_{\max }$ for glycylglycine seems to indicate that the membrane digestion is not involved in the absorption of this dipeptide. If the membrane digestion and subsequent $\mathrm{Na}^{+}$dependent transport of glycine are involved, $J_{\max }$ value in the presence of $\mathrm{Na}^{+}$ must significantly exceed that in the absence of $\mathrm{Na}^{+}$, since glycine transport is absolutely dependent on $\mathrm{Na}^{+}$and its $J_{\max }$ value is much higher than that for glycylglycine.

Glycylglycine dipeptidase is known to be mainly localized in the cytosol and a small fraction is found in the membrane fraction (Peters, 1970, 1973). The dipeptidase is also known to be activated by $\mathrm{Co}^{++}$significantly. However, Cheeseman and Smyth (1971) demonstrated that the stimulation of the enzyme by $\mathrm{Co}^{++}$was found in the homogenate of the epithelial cells but not in the intact everted sac preparation. These findings also support the view that the membrane digestion is unimportant in the absorption of this dipeptide.

Recently, SigRIST-NeLSON (1975) showed that, in the purified brush border membrane vesicles, glycyl-L-leucine was transported as such across the membrane and subsequently it was hydrolysed into amino acids within $5 \mathrm{~min}$ at $25^{\circ} \mathrm{C}$. In her vesicle preparations, cytosol enzymes were absent since no lactic acid dehydrogenase activity was present. Therefore, only the membrane-bound dipeptidase may be responsible for the intravesicular hydrolysis. In the present study, all 
glycylglycine transported were hydrolysed into glycine within 2 min at $37^{\circ} \mathrm{C}$. Probably, both membrane-bound and cytosol glycylglycine dipeptidases are responsible for such a rapid intracellular hydrolysis of this dipeptide.

The properties of glycine transport by the present preparation were somewhat different from those of glycine transport in the rabbit ileum. In the latter glycine is transported by two systems, one is neutral amino acid system and the other imino acid transport system (PeTERson et al., 1970). Also in rabbit ileum, significant amount of glycine is transported even in the absence of $\mathrm{Na}^{+}$. In the present preparations, glycine transport conformed to single Michaelis-Menten kinetics in a wide range of its concentration $(1.25-40 \mathrm{mM})$ and no evidence was obtained for such a dual transport mechanism. Also, no glycine entry was observed in $\mathrm{Na}^{+}$-free medium. Probably, such different properties may be due to the species difference.

Mutual inhibition observed between glycylglycine and glycine is apparently contradictory to the conclusion that the transport systems for these substances are distinct. Although inhibitory effect of glycylglycine on glycine transport was not analyzed in detail, relatively small inhibition led us to an interpretation in terms of some mechanisms other than direct competition for a common carrier. Mutual inhibition is usually observed between $\mathrm{Na}^{+}$-linked transport of sugars and amino acids or among amino acids of different groups. Such mutual inhibition may be partly due to diminution of $\mathrm{Na}^{+}$gradient across the transporting membrane (trans $\mathrm{Na}^{+}$effect) as suggested by SEMENZA (1971). Also, inhibition through the reduction of transmembrane potential may be probable since most $\mathrm{Na}^{+}$-linked transport processes for sugars and amino acids, except acidic amino acids, are dependent on the electric field across the membrane and induce depolarization of the transmembrane potential (MURER and HoPfER, 1974; HOSHI and KIKUTA, 1977).

On the other hand, inhibition of glycylglycine transport by glycine observed in the absence of $\mathrm{Na}^{+}$can not be explained on the basis of the "trans $\mathrm{Na}^{+}$effect" or the transmembrane depolarization and voltage-dependent nature of transport. Since glycine is not translocated without $\mathrm{Na}^{+}$at least in the present preparation, this inhibition is considered to be related to the interaction at the step of binding of glycylglycine to its carriers. Similar interaction at the step of binding to carrier sites has been reported for $\mathrm{K}^{+}$effect on $\mathrm{Na}^{+}$-amino acid interaction (FRIzzELL and SChUltz, 1970; AHEARN, 1976).

A very strong inhibition of glycylglycine transport by glycyl-L-leucine may not be explained without considering the competition for common carriers.

In relation to different characteristics of glycine and glycylglycine transport as observed in the present study, the observations made by ADIBI et al. (1974) are of interest. They compared the absorption of glycine and glycylglycine by the jejunum between healthy volunteers and sprue-like patients. They found that the absorption rates for both substances were markedly lower in the patients, but the reduction of the rate was much greater in glycine absorption than in glycylglycine (15-fold decrease versus 4 -fold decrease). Such greater susceptibility of glycine 
transport may be related to its strong dependence on $\mathrm{Na}^{+}$. $\mathrm{Na}^{+}$-linked active transport requires normal operation of $\mathrm{Na}^{+}-\mathrm{K}^{+}$pump at the basolateral membrane and metabolic supply of ATP to the pump (Schultz and CURran, 1970). On the other hand, poorly $\mathrm{Na}^{+}$-dependent transport and subsequent intracellular hydrolysis of glycylglycine are much less dependent on the function of the $\mathrm{Na}^{+}-\mathrm{K}^{+}$ pump and on the metabolic supply of ATP. Therefore, it seems quite reasonable that diffuse intestinal epithelial lesion more strongly affects glycine transport than glycylglycine transport.

\section{REFERENCES}

Addison, J. M., Burston, D., and Matthews, D. M. (1972) Evidence for active transport of the dipeptide glycylsarcosine by hamster jejunum in vitro. Clin. Sci., 43: 907-911.

Addison, J. M., Burston, D., Payne, J. W., Wilkinson, S., and Matthews, D. M. (1975) Evidence for active transport of tripeptides by hamster jejunum in vitro. Clin. Sci. Mol. Med., 49: 305-312.

AdiBI, S. A. (1971) Intestinal transport of dipeptides in man: Relative importance of hydrolysis and intact absorption. J. Clin. Invest., 50: 2266-2275.

Adibi, S. A., Fogel, M. R., and Agrawal, R. M. (1974) Comparison of free amino acid and dipeptide absorption in the jejunum of sprue patients. Gastroenterology, 67: 586-591.

Adibi, S. A. and Soleimanpour, M. R. (1974) Functional characterization of dipeptide transport system in human jejunum. J. Clin. Invest., 53: 1368-1374.

AHEARN, G. A. (1976) Co-transport of glycine and sodium across the mucosal border of the midgut epithelium in the marine shrimp, Penaeus marginatus. J. Physiol., 258: 499-520.

Chemseman, C. I. and Smyth, D. H. (1971) Site of intestinal hydrolysis of glycylglycine. $J$. Physiol., 218: 39 P-40 P.

Crane, R. K. (1968) A concept of the digestive-absorptive surface of the small intestine. In: Handbook of Physiology, Section 6, Alimentary canal, Vol. 5, ed. by CoDE, C. F. Am. Physiol. Soc., Washington, D. C., pp. 2535-2542.

Curran, P. F., Schultz, S. G., Chez, R. A., and Fuisz, R. E. (1967) Kinetic relations of the Na-amino acid interaction at the mucosal side. J. Gen. Physiol., 50: 1261-1286.

Frizzell, R. A. and Schultz, S. G. (1970) Effects of monovalent cations on the sodiumalanine interaction in rabbit ileum. J. Gen. Physiol., 56: 362-383.

Hoshi, T., Suzuki, Y., Kusachi, T., and Igarashi, Y. (1976) Interrelationship between sugarevoked increases in transmural potential difference and sugar influxes across the mucosal border in the small intestine. Tohoku J. Exp. Med., 119: 201-209.

HoshI, T. and KIKUTA, Y. (1977) Effects of organic solute-sodium co-transport on the transmembrane potentials and resistance parameters of the proximal tubule of Triturus kidney. In: Electrophysiology of the Nephron (INSERM colloques), ed. by ANAGNOSTOPOULUS, T. INSERM, 67: 135-160.

Igarashi, Y., Saito, Y., HimukaI, M., and Hoshi, T. (1976) Interpretation of disaccharidedependent electrical potential differences in the small intestine. Jap. J. Physiol., 26: 79-92.

KoHN, P. G., SмYтн, D. H., and Wright, E. M. (1968) Effects of amino acids, dipeptides and disaccharides on the electrical potential across rat small intestine. J. Physiol., 196: 723-746.

Matthews, D. M. (1975) Intestinal absorption of peptides. Physiol. Rev., 55: 537-608.

Matthews, D. M., Addison, J. M., and Burston, D. (1974) Evidence for active transport of the dipeptide carnosine ( $\beta$-alanyl-L-histidine) by hamster jejunum in vitro. Clin. Sci. Mol. Med., 46: 693-705.

Vol. 28, No. 4, 1978 
Matthews, D. M., Craft, I. L., Geddes, D. M., Wise, I. J., and Hyde, C. W. (1968) Absorption of glycine and glycine peptides from the small intestine of the rat. Clin. Sci., 35: 415424.

Murer, H. and Hopfer, U. (1974) Demonstration of electrogenic $\mathrm{Na}^{+}$-dependent D-glucose transport in intestinal brush border membranes. Proc. Natl. Acad. Sci. USA, 71: 484-488.

Newey, H. and Smyth, D. H. (1962) Cellular mechanisms in intestinal transfer of amino acids. J. Physiol., 164: 527-551.

PeTERs, T. J. (1970) The subcellular localization of di- and tri-peptide hydrolase activity in guinea pig small intestine. Biochem. J., 120: 195-203.

Peters, T. J. (1973) The hydrolysis of glycine oligopeptides by guinea pig intestinal mucosa and by isolated brush border. Clin. Sci. Mol. Med., 45: 803-816.

Peterson, S. C., Goldner, A. M., and Curran, P. F. (1970) Glycine transport in rabbit ileum. Am. J. Physiol., 219: 1027-1032.

Sardesai, V. M. and Provido, H. M. (1970) The determination of glycine in biological fluid. Clin. Chim. Acta, 29: 67-71.

Schultz, S. G. and Curran, P. F. (1970) Coupled transport of sodium and organic solute. Physiol. Rev., 50: 637-718.

Schultz, S. G., Yu-Yu, L., Alvarez, O. O., and Curran, P. F. (1970) Dicarboxylic amino acid influx across brush border of rabbit ileum. Effects of amino acid charge on the sodiumamino acid interaction. J. Gen. Physiol., 56: 621-639.

SEMENZA, F. (1971) On the mechanism of mutual inhibition among sodium-dependent transport systems in the small intestine. A hypothesis. Biochim. Biophys. Acta, 241: 637-649.

SigRIST-NELSON, K. (1975) Dipeptide transport in isolated intestinal brush border membrane. Biochim. Biophys. Acta, 394: 220-226.

Ugolev, A. M. (1974) Membrane (contact) digestion. In: Biomembranes, Vol. 4A, Intestinal Absorption, ed. by Smyth, D. H. Plenum Press, London, New York, pp. 285-362. 